\title{
Are medical students in Palestine adequately trained to care for individuals with autism spectrum disorders? A multicenter cross-sectional study of their familiarity, knowledge, confidence, and willingness to learn
}

Ramzi Shawahna ${ }^{1,2^{*}}$, Mohammad Jaber $^{3,4}$, Nourhan Yahya ${ }^{3}$, Firdaous Jawadeh ${ }^{3}$ and Shahd Rawajbeh ${ }^{3}$

\begin{abstract}
Background: Medical students are the future workforce of physicians in primary, secondary, tertiary, and highly specialized care centers. The present study was undertaken to assess familiarity, knowledge, confidence, of medical students with regard to autism spectrum disorders (ASDs).

Methods: This multicenter study was conducted in a cross-sectional design among medical students in the 3 main universities in Palestine. In addition to the sociodemographic and academic details, the questionnaire measured familiarity (8-items), knowledge (12-items), confidence and willingness to learn (5-items) with regard to ASDs.

Results: The questionnaire was completed by309 medical students (response rate $=77.3 \%$ ). The median familiarity, knowledge, and confidence scores were $50 \%$ (42.5\%, $57.5 \%), 50 \%(41.7 \%, 66.7 \%)$, and $60.0 \%$ (54.0\%, 68.0 \%), respectively. There was a positive moderate correlation between familiarity and knowledge scores (Spearman's rho $=0.29, \mathrm{p}$-value $<0.001$ ) and familiarity and confidence scores (Spearman's rho $=0.34$, p-value $<0.001$ ). Medical students who have received a course on autism were 3.08-fold (95\% C.I. of 1.78-5.31) more likely to score $\geq 50 \%$ on the familiarity items compared to those who did not receive a course. The medical students who were in their clinical academic stage, who received a course on ASDs, and those who interacted with individuals with ASDs were 2.36 -fold ( $95 \%$ C.I. of 1.34-4.18), 2.66-fold (95 \% C.I. of 1.52-4.65), and 2.59-fold (95\% C.I. of 1.44-4.63) more likely to score $\geq 50 \%$ on the knowledge items. Medical students who reported high satisfaction with their social life were 2.84-fold (95\% C.I. of 1.15-7.00) more likely to score $\geq 50 \%$ on the confidence items.
\end{abstract}

\footnotetext{
* Correspondence: ramzi_shawahna@hotmail.com

'Department of Physiology, Pharmacology and Toxicology, Faculty of

Medicine and Health Sciences, An-Najah National University, P.O. Box 7, New

Campus, Building: 19, Office: 1340, Nablus, Palestine

${ }^{2}$ An-Najah BioSciences Unit, Centre for Poisons Control, Chemical and

Biological Analyses, An-Najah National University, Nablus, Palestine

Full list of author information is available at the end of the article
}

C C The Author(s). 2021 Open Access This article is licensed under a Creative Commons Attribution 4.0 International License, which permits use, sharing, adaptation, distribution and reproduction in any medium or format, as long as you give appropriate credit to the original author(s) and the source, provide a link to the Creative Commons licence, and indicate if changes were made. The images or other third party material in this article are included in the article's Creative Commons licence, unless indicated otherwise in a credit line to the material. If material is not included in the article's Creative Commons licence and your intended use is not permitted by statutory regulation or exceeds the permitted use, you will need to obtain permission directly from the copyright holder. To view a copy of this licence, visit http://creativecommons.org/licenses/by/4.0/ The Creative Commons Public Domain Dedication waiver (http://creativecommons.org/publicdomain/zero/1.0/) applies to the data made available in this article, unless otherwise stated in a credit line to the data. 
Conclusions: The present study identified considerable awareness and knowledge gaps among medical students with regard to ASDs. Medical students in this study reported low confidence in their ability to provide healthcare services to individuals with ASDs. Appropriately designed educational interventions might improve familiarity, knowledge, and confidence of medical students. More studies are still needed to investigate if such interventions can improve healthcare services for individuals with ASDs.

Keywords: Autism spectrum disorders, Awareness, Knowledge, Education, Medical students

\section{Background}

Since their description by Kanner in 1943, autism spectrum disorders (ASDs) have evolved from disorders that occur rarely to one of the fastest growing developmental disorders $[1,2]$. Based on data from the Centers for Disease Control and Prevention (CDC), ASDs occur at a rate of 1 in 54 children [3, 4]. Considering the high prevalence rates in every nation of the world, ASDs have now evolved as an emerging public health issue $[1,2]$. Research studies have shown that ASDs are more prevalent among males compared to females [2]. Additionally, epidemiological studies have shown that ASDs were more prevalent compared to pediatric cancers, juvenile diabetes, and acquired immunodeficiency syndrome in children combined $[5,6]$. Studies conducted in different countries have shown that ASDs were not linked to racial, ethnic, and/or socioeconomic groups [7]. In the absence of large epidemiological surveys, little is known on the incidence and prevalence of ASDs among the Palestinians [6, 8]. Additionally, Palestinian refugees were excluded from studies conducted in the neighboring Lebanon to estimate prevalence of ASDs which was estimated between 49 and 513 per 10,000 [9, 10]. A recent systematic review and meta-analysis estimated a pooled prevalence rate of ASDs at $0.36 \%$ (95\% CI: $0.16-$ $0.79 \%)$ among Asians [11]. The study included populations from South, East, and West Asia. Awareness of ASDs among the Palestinians has been growing and the national disability survey of the Palestinian Central Bureau of Statistics included ASDs within the category of "learning difficulties" [8].

Limitations in communication, social interactions, and behavioral development are typically seen among individuals with ASDs [12, 13]. Like other neurodevelopmental disorders, ASDs are not curable. However, health regulatory authorities like the US Food and Drug Administration (FDA) have approved some pharmacological and nonpharmacological management options that aim to alleviate some of the signs and symptoms that could be associated with ASDs [14, 15]. Today, prescription of pharmacotherapeutic options to manage and alleviate behavioral symptoms of ASDs like tantrums, aggressiveness, hyperactivity, and anxiety is increasingly popular in clinical practice [14-17]. Analysis of medication prescription has shown increasing volumes of psychoactive drugs among individuals with ASDs $[17,18]$. Currently, the antipsychotics risperidone and aripiprazole are approved by the FDA to alleviate behavioral symptoms of ASDs [18]. Additionally, stimulants of the central nervous system, anxiolytics, and antidepressant drugs are also used in the management of symptoms of ASDs [19, 20].

In Palestine, healthcare services for individuals with ASDs are provided by 4 main sectors: (1) the public sector (healthcare facilities of the Palestinian Ministry of Health), (2) the private sector (for-profit healthcare facilities), (3) non-governmental organizations (NGOs), and (4) healthcare facilities of the United Nations Relief and Works Agency (UNRWA) [6, 8]. As the public healthcare services often fall short for some diagnostic and health needs of the patients, therefore, diagnostic, psychosocial support, and rehabilitation services to individuals with ASDs are predominantly provided by the private sector and NGOs. The Ministry of Health often subsidize diagnostic and care services within the private sector or NGOs to the needy patients who cannot afford the costs in case these services were not provided by the public healthcare facilities.

Although in contemporary practice, individuals with ASDs might receive services from specialty providers like behavioral optometrists, clinical psychologists, counsellors/psychotherapists, psychiatrists, and occupational therapists, physicians are the backbone of healthcare delivery in the majority of the healthcare systems around the world. In resource deficient settings and in the absence of multi-healthcare provider approaches to healthcare, physicians are supposed to make diagnosis, prescribe medications, and guide the treatment plans for patients including those with ASDs. Diagnosis and management of individuals with ASDs can be highly challenging in clinical practice $[21,22]$. This is particularly true for pharmacotherapy as individuals with ASDs were more susceptible to the side effects of these pharmacotherapeutic modalities compared to individuals without ASDs [23, 24]. Additionally, individuals with ASDs were shown to exhibit paradoxical reactions to some drugs [25]. Medical students are the future workforce of physicians in all specialties. With the increasing prevalence of ASDs, future physicians are expected to encounter and provide care for this segment of the society. Therefore, future physicians should be knowledgeable of 
ASDs [26]. Inadequately trained physicians or physicians with inadequate familiarity and knowledge of ASDs are less likely to provide quality care for individuals with ASDs compared with familiar and knowledgeable physicians. Provision of suboptimal care might have serious consequences on the health and quality of life of the affected patients. Unfortunately, studies have shown that ASDs are still not adequately understood by healthcare providers including physicians who are supposed to be knowledgeable of health issues of people with ASDs $[6,27]$. Physicians are supposed to make or help make diagnosis of ASDs, provide counseling to families or caregivers of the affected individuals, manage symptoms, and make appropriate referrals to specialty services when needed. With the increasing prevalence of ASDs, those individuals are increasingly encountered in primary healthcare practice. Physicians should also be able to help individuals and their families to benefit from resources allocated within the community for the individuals and their families.

Assessing familiarity, knowledge, confidence, and willingness to learn of medical students on the different aspects of ASDs can be important in measuring and benchmarking quality of medical training and preparing future physicians who would provide healthcare to individuals with ASDs. Familiarity, knowledge, confidence, and willingness to learn of medical students on ASDs were not previously assessed among medical students trained in Palestine. Therefore, this study was conducted to: (a) assess familiarity of the medical students with individuals with ASDs, (b) assess familiarity of the medical students with symptoms, diagnosis, treatment options, and community resources to help people with ASDs and their families, (c) assess knowledge of the medical students with etiology, prevalence, and treatment of ASDs, (d) assess confidence of the medical students to provide care/counsel people with ASDs and willingness to learn about ASDs, (e) investigate correlations between familiarity, knowledge, and confidence scores of the medical students, (f) investigate associations between sociodemographic and academic variables of the students with familiarity, knowledge, and confidence scores, and (g) identify predictors of higher familiarity, knowledge, and confidence scores.

\section{Methods}

\section{Study context and settings}

This multicenter study was conducted among Palestinian medical students in the three main universities in Palestine. The study was conducted in the context of assessing training of future physicians to care for individuals with ASDs. The Doctor of Medicine (MD) program offered at Palestinian universities consists of 130 credit hours of basic courses and 135 credit hours of hospital/ clinic-based training. The students often complete the MD program in 6 academic years. Fresh graduates have to receive a 1-year internship before they could be licensed to practice medicine in Palestine.

\section{Study design}

This multicenter study was conducted in a crosssectional design using a questionnaire as the study tool. Therefore, the study was conducted and reported in adherence to the guidelines for reporting cross-sectional studies in which a questionnaire was used as the study tool [28-30]. Adherence to the guidelines is shown in Supplementary Table S1. The guidelines ensured reporting the study design, objectives, settings, recruitment process, sampling, participants, representativeness, study tool, reliability/validity, psychometrics, data analysis, main results, interpretation of the findings, discussion of the strengths, limitations, and generalizability.

\section{The study population, sample size, and inclusion criteria}

This study population was medical students in the 3 major universities in Palestine. The number of medical students needed in this study was estimated using a sample size estimator that is accessible online (www. raosoft.com). The sample size was estimated for a population of 3,500 medical students. The number of medical students needed for this study was estimated at a $95 \%$ confidence interval (C.I.) with a $5 \%$ margin of error. The sample size needed was 347 students.

Medical students were eligible for inclusion in this study if they were: (a) 18 years and older, (b) enrolled in an MD program in a Palestinian university, (c) willing to respond to items in a questionnaire, and (d) willing to provide informed consent. The medical students were approached and invited by the field researchers from the 3 major universities in Palestine. The field researchers explained the study objectives to the potential participants and provided them with the questionnaire. The medical students consented to participate without any financial or academic incentives.

\section{The study questionnaire}

The questionnaire used in this study was adopted and modified from previous studies that were conducted to assess awareness and knowledge of healthcare providers with regard to people with ASDs [5, 6, 31, 32]. The questionnaire used in this study consisted of 4 sections. Section 1 collected the sociodemographic and academic variables of the medical students like: gender, place of residence, and academic years/stage. The medical students were also asked to state if they have had a course/ part of a course on ASDs, or had interacted with somebody with ASDs, and who was that person. Additionally, the medical students were asked to state if they were 
satisfied with their academic achievement, satisfied with their financial status, and satisfied with their social status. Section 2 contained 8 items to collect familiarity of the medical students with symptoms, diagnosis, treatment options, and community resources to help people with ASDs and their families. On each item, the medical students had to rate their familiarity on a Likert-scale of 1-5 ( 1 = completely unfamiliar, $5=$ completely familiar). Section 3 contained 12 items to measured knowledge of medical students with regard to etiology, prevalence, and treatment of ASDs. On each knowledge item, the medical students had to respond by either true/false/I don't know. Section 4 contained 5 items to measure confidence of the medical students to confidence of the medical students to provide care/counsel people with ASDs and willingness to learn about ASDs. On each item, the medical students had to indicate their level of disagreement/agreement on a Likert-scale of 1-5 (1= strongly disagree, 5 = strongly agree).

\section{Pilot testing of the questionnaire}

Before the questionnaire was used in the larger study, the questionnaire was pilot tested with 18 medical students who did not take part in the larger study. The medical students were asked to read and rated the items for clarity and comprehension. Some items were rephrased for clarity based on the feedback obtained in the pilot testing. The 18 medical students were asked to respond to the questionnaire in two consecutive rounds. The time between both administrations was $30 \mathrm{~min}-$ $2 \mathrm{~h}$. Stability of scores was assessed using the test-retest method. The internal consistency (item relatedness) was assessed using Cronbach's alpha. A Pearson's correlation coefficient $(r)$ of $>0.8$ indicated acceptable reliability and a Cronbach's alpha of $>60 \%$ indicated acceptable internal consistency. The internal consistency of familiarity, knowledge, and confidence items were assessed separately.

\section{Data analysis}

Familiarity scores were summed and could range from 8 to 40. For each correct answer, students were awarded 1 point and 0 point for each incorrect/I don't know answer. Knowledge scores were summed and could range from 0 to 12 . Confidence scores were summed and could range from 5 to 25 . All scores were also converted into percentages.

The difficulty index (D) was used to psychometrically assess the difficulty of each knowledge item. The D values were ratios between correct answers/total number of answers for each item. The knowledge items were attributed as follows: (a) a very difficult class: when $20 \%<$ D, (b) difficult class: when $20 \% \leq \mathrm{D}<40 \%$, (c) moderate difficulty class: when $40 \% \leq \mathrm{D}<60 \%$, (d) easy class: when $60 \% \leq \mathrm{D}<80 \%$, and (e) very easy class: when $\mathrm{D} \geq$ $80 \%$ [6].

The data were assessed for normal distribution using the Kolmogorov-Smirnov test. As the data were not normally distributed, the data were expressed using medians and interquartile range (Q1, Q3). Spearman's rank correlations, Pearson's Chi-Square test, and/or Fisher's exact test were used to compare categorical data, as appropriate. To control potentially confounding variables and assess the strength of association, a multiple logistic regression model was used to determine predictors of scoring $\geq 50 \%$ on the familiarity, knowledge, and confidence items. All variables were retained in the multiple logistic regression model. A $p$-value $<0.05$ was considered as statistically significant.

\section{Ethics approval and consent to participate}

This multicenter cross-sectional study was conducted in adherence to the international guidelines and regulations including those in the Declaration of Helsinki and the ones followed at An-Najah National University. The study received ethical approval from the Institutional Review Board of An-Najah National University. The medical students who participated in this study provided written informed consent.

\section{Results}

Reliability and internal consistency of the items in the questionnaire

The Pearson's $r$ of the scores in both rounds was 0.97 with a $p$-value $<0.001$ which indicated excellent reliability (stability of scores over a short period of time). The Cronbach's alpha values were $0.81,0.68$, and 0.66 for the familiarity, knowledge, and confidence items, respectively. The values indicated good relatedness (internal consistency) of the items used for each dimension.

\section{Sociodemographic and academic variables of the medical students}

Of the 400 medical students invited, the questionnaire was completed by 309 medical students, giving a response rate of $77.3 \%$. The sociodemographic and academic variables of the medical students who participated in this study are shown in Table 1 . Of the study participants, female students were well represented (71.8\%) which reflected the high percentage of female medical students in the MD program in the Palestinian universities, $58.6 \%$ of the medical students lived in urban areas, $61.2 \%$ were in their clinical stage of the MD program (4th to 6th year), the vast majority (97.7\%) of the medical students were satisfied with their academic achievement, $94.2 \%$ were satisfied with their financial status, $88.7 \%$ were satisfied with their social status, $65.7 \%$ reported that they had a course/part of a course 
Table 1 Sociodemographic and academic variables of the medical students who participated in this study $(n=309)$

\begin{tabular}{|c|c|c|}
\hline Variable & $\mathbf{n}$ & $\%$ \\
\hline \multicolumn{3}{|l|}{ Gender } \\
\hline Male & 87 & 28.2 \\
\hline Female & 222 & 71.8 \\
\hline \multicolumn{3}{|l|}{ Place of residence } \\
\hline Countryside & 128 & 41.4 \\
\hline Urban & 181 & 58.6 \\
\hline \multicolumn{3}{|l|}{ Academic stage } \\
\hline Basic stage (1st to $3 r d$ year) & 120 & 38.8 \\
\hline Clinical stage (4th to 6th year) & 189 & 61.2 \\
\hline \multicolumn{3}{|c|}{ Self-rated satisfaction with academic achievement } \\
\hline Not satisfied & 7 & 2.3 \\
\hline Satisfied & 302 & 97.7 \\
\hline \multicolumn{3}{|c|}{ Self-rated satisfaction with financial status } \\
\hline Not satisfied & 18 & 5.8 \\
\hline Satisfied & 291 & 94.2 \\
\hline \multicolumn{3}{|c|}{ Self-rated satisfaction with social status } \\
\hline Not satisfied & 35 & 11.3 \\
\hline Satisfied & 274 & 88.7 \\
\hline \multicolumn{3}{|c|}{ Had a course/part of a course on ASDs } \\
\hline No & 106 & 34.3 \\
\hline Yes & 203 & 65.7 \\
\hline \multicolumn{3}{|c|}{ Interacted with somebody with ASDs } \\
\hline No & 204 & 66.0 \\
\hline Yes & 105 & 34.0 \\
\hline
\end{tabular}

on ASDs, and $34.0 \%$ reported that they had interacted with someone with ASDs (Table 1).

\section{Interaction with somebody with ASDs}

Of the medical students who reported interacting with someone with ASDs, $40.0 \%$ reported interacting with a relative with ASDs, $38.1 \%$ reported interacting with somebody from the neighborhood with ASDs, and $23.8 \%$ interacted with an individual with ASDs during their training. Details of the responses of the medical students are shown in Table 2.

\section{Familiarity of the medical students with symptoms, diagnosis, treatment options, and community resources to help people with ASDs and their families}

There was a positive moderate correlation between familiarity scores and knowledge scores (Spearman's rho $=0.29, p$-value $<0.001)$. Similarly, there was a moderate positive correlation between familiarity scores and confidence scores (Spearman's rho $=0.34, p$-value $<0.001$ )

The median familiarity score was $50 \%$ with an interquartile range of $(42.5 \%, 57.5 \%)$. The distribution of the
Table 2 Interaction with somebody with ASDs

\begin{tabular}{lll}
\hline Who was the person with autism spectrum disorder & $\mathbf{n}^{*}$ & \%* $^{*}$ \\
\hline A relative & 42 & 40.0 \\
Somebody from the neighborhood & 40 & 38.1 \\
An individual during my training & 25 & 23.8 \\
A family member & 16 & 15.2 \\
A relative of a friend & 14 & 13.3
\end{tabular}

"Percentages were calculated from the number of the medical students who reported interacting with somebody with ASDs $(n=105)$. The numbers do not sum to the total number of the medical students who participated in this study and the percentages do not sum to $100 \%$

responses of the medical students on the familiarity items is shown in Table 3. Worrisomely, a considerable percentage of the medical students reported inadequate familiarity with symptoms, diagnosis, treatment options, and community resources to help people with ASDs and their families as indicated by the percentage of the medical students who rated their familiarity on the Likertscale 1-3 (Not familiar at all to somewhat familiar) and the low percentage of students who rated their familiarity on the Likert-scale 4-5 (familiar to completely familiar). Of the medical students, $78.6 \%$ reported in adequate familiarity with the symptoms of ASDs, $92.2 \%$ reported inadequate familiarity with the tools used to diagnose ASDs, $81.9 \%$ reported inadequate familiarity with the classes of medications that can be used in treating the symptoms of ASDs, $72.5 \%$ reported inadequate familiarity with the behaviors associated with ASDs that medications seek to alleviate, $92.2 \%$ reported inadequate familiarity with the doses of medications used in the treatment of ASDs symptoms, $87.4 \%$ reported inadequate familiarity with the various side effects produced by medications used in the treatment of ASDs symptoms, $84.8 \%$ reported inadequate familiarity with how to help families sort through information to make informed decisions about their child with ASDs, and 87.1\% reported inadequate familiarity with community resources in their region that can be used for referral of a child who is exhibiting symptoms commonly associated with ASDs.

\section{Knowledge of the medical students with regard to etiology, prevalence, and treatment of ASDs}

On the knowledge items, the median score was $50 \%$ with an interquartile range of $(41.7 \%, 66.7 \%)$. Detailed responses of the medical students on each knowledge item are shown in Table 4.

Despite some high awareness areas like awareness of impairments in social interaction, communication or language, and behavioral development among children with ASDs (item \#2) which was correctly answered by $93.2 \%$ of the medical students. Several knowledge gaps were identified as indicated by the number of incorrect 
Table 3 Familiarity of the medical students with symptoms, diagnosis, treatment options, and community resources to help people with ASDs and their families

\begin{tabular}{|c|c|c|c|c|c|c|c|c|c|c|c|}
\hline \multirow[b]{2}{*}{$\#$} & \multirow[b]{2}{*}{ Familiarity item } & \multicolumn{2}{|c|}{ Not familiar at all } & \multicolumn{2}{|c|}{ Not familiar } & \multicolumn{2}{|c|}{$\begin{array}{l}\text { Somewhat } \\
\text { familiar }\end{array}$} & \multicolumn{2}{|c|}{ Familiar } & \multicolumn{2}{|c|}{$\begin{array}{l}\text { Completely } \\
\text { familiar }\end{array}$} \\
\hline & & $\mathrm{n}$ & $\%$ & $\mathrm{n}$ & $\%$ & $\mathrm{n}$ & $\%$ & $\mathrm{n}$ & $\%$ & $\mathrm{n}$ & $\%$ \\
\hline & How would you rate your familiarity with & & & & & & & & & & \\
\hline 1 & Different symptoms of ASDs & 13 & 4.2 & 63 & 20.4 & 167 & 54.0 & 53 & 17.2 & 13 & 4.2 \\
\hline 2 & Different tools used to diagnose ASDs & 50 & 16.2 & 142 & 46.0 & 93 & 30.1 & 18 & 5.8 & 6 & 1.9 \\
\hline 3 & $\begin{array}{l}\text { Different classes of drugs (e.g., antidepressants, } \\
\text { antipsychotics, central nervous } \\
\text { system stimulants) that can be used in the } \\
\text { management of the symptoms } \\
\text { of ASDs }\end{array}$ & 38 & 12.3 & 107 & 34.6 & 108 & 35.0 & 52 & 16.8 & 4 & 1.3 \\
\hline 4 & $\begin{array}{l}\text { Specific behaviors associated with ASDs that } \\
\text { drugs seek to alleviate (e.g., } \\
\text { self-injury, hyperactivity, and } \\
\text { obsessive-compulsive disorder) }\end{array}$ & 24 & 7.8 & 68 & 22.0 & 132 & 42.7 & 68 & 22.0 & 17 & 5.5 \\
\hline 5 & $\begin{array}{l}\text { Doses of drugs used in the management of } \\
\text { symptoms of ASDs }\end{array}$ & 95 & 30.7 & 143 & 46.3 & 47 & 15.2 & 20 & 6.5 & 4 & 1.3 \\
\hline 6 & $\begin{array}{l}\text { Various side effects produced by drugs used } \\
\text { in the management of symptoms of ASDs } \\
\text { (e.g., irritation, sedation, and extrapyramidal } \\
\text { symptoms) }\end{array}$ & 47 & 15.2 & 131 & 42.4 & 92 & 29.8 & 34 & 11.0 & 5 & 1.6 \\
\hline 7 & $\begin{array}{l}\text { How to help families sort through information } \\
\text { to make informed decisions } \\
\text { about their child with ASDs }\end{array}$ & 30 & 9.7 & 121 & 39.2 & 111 & 35.9 & 42 & 13.6 & 5 & 1.6 \\
\hline 8 & $\begin{array}{l}\text { Community resources available in the region } \\
\text { that can be used for referral of a child who is } \\
\text { exhibiting symptoms commonly associated } \\
\text { with ASDs }\end{array}$ & 44 & 14.2 & 125 & 40.5 & 100 & 32.4 & 33 & 10.7 & 7 & 2.3 \\
\hline
\end{tabular}

Table 4 Knowledge of the medical students with etiology, prevalence, and treatment of ASDs

\begin{tabular}{|c|c|c|c|c|c|c|c|c|}
\hline \multirow[b]{2}{*}{$\#$} & \multirow[b]{2}{*}{ Knowledge item } & \multicolumn{2}{|c|}{ True } & \multicolumn{2}{|c|}{ False } & \multicolumn{2}{|c|}{ I don't know } & \multirow[b]{2}{*}{ D } \\
\hline & & $\mathrm{n}$ & $\%$ & $\mathrm{n}$ & $\%$ & $\mathrm{n}$ & $\%$ & \\
\hline 1 & ASDs are developmental disorders? & 187 & 60.5 & 57 & 18.4 & 65 & 21.0 & Easy \\
\hline 2 & $\begin{array}{l}\text { Children with ASDs have impairments in social interaction, } \\
\text { communication or language, and behavioral development? }\end{array}$ & 288 & 93.2 & 6 & 1.9 & 15 & 4.9 & Very easy \\
\hline 3 & ASDs occur more commonly among males than females? & 123 & 39.8 & 27 & 8.7 & 159 & 51.5 & Difficult \\
\hline 4 & ASDs are more prevalent than juvenile diabetes? & 40 & 12.9 & 58 & 18.8 & 211 & 68.3 & Very difficult \\
\hline 5 & ASDs are more prevalent than Down syndrome? & 66 & 21.4 & 82 & 26.5 & 161 & 52.1 & Difficult \\
\hline 6 & ASDs are curable? & 45 & 14.6 & 193 & 62.5 & 71 & 23.0 & Easy \\
\hline 7 & $\begin{array}{l}\text { Risperidone and aripiprazole have been approved by the } \\
\text { health authorities for the treatment of irritability associated } \\
\text { with ASDs? }\end{array}$ & 53 & 17.2 & 13 & 4.2 & 243 & 78.6 & Very difficult \\
\hline 8 & Vaccines can cause ASDs? & 23 & 7.4 & 207 & 67.0 & 79 & 25.6 & Easy \\
\hline 9 & ASDs exist only in childhood? & 59 & 19.1 & 199 & 64.4 & 51 & 16.5 & Easy \\
\hline 10 & $\begin{array}{l}\text { ASDs are caused because of emotionally distant, rejecting } \\
\text { parents? }\end{array}$ & 102 & 33.0 & 133 & 43.0 & 74 & 23.9 & Moderate \\
\hline 11 & Genetic factors play a major role in the etiology of ASDs? & 219 & 70.9 & 31 & 10.0 & 59 & 19.1 & Easy \\
\hline 12 & ASDs are rare disorder? & 37 & 12.0 & 199 & 64.4 & 73 & 23.6 & Easy \\
\hline
\end{tabular}


answers/I don't know answers. Of the medical students, $70.9 \%$ could correctly answer the item on the role of genes in ASDs (item \# 11), 67.0\% could correctly answer the item on the myth that vaccines can cause autism (item \#8), 64.4\% could correctly answer the item on the existence of ASDs beyond childhood (item \# 9), 64.4\% could correctly answer the item on the high prevalence of ASDs (item \# 12), $62.5 \%$ could correctly answer the item on the incurability of ASDs (item \# 6), $60.5 \%$ could correctly answer the item on the spectrum disorders as developmental disorders (item \#1), $43.0 \%$ could correctly answer the item on the myth that ASDs are caused by emotionally distant, rejecting parents (item \# 10), $39.8 \%$ could correctly answer the item on the higher incidence of ASDs among males (item \# 3), $21.4 \%$ could correctly answer the item on the higher prevalence of ASDs compared to Down syndrome (item \# 5), $17.2 \%$ could correctly answer the item on the use of risperidone and aripiprazole in the treatment of irritability associated with ASDs (item \#7), and $12.9 \%$ could correctly answer the item on the higher prevalence of ASDs compared to juvenile diabetes (item \# 4).

\section{Confidence of the medical students to provide care/counsel people with ASDs and willingness to learn about ASDs}

The median confidence score was $60.0 \%$ with an interquartile range of $(54.0 \%, 68.0 \%)$. Detailed responses of the medical students on each confidence and willingness to learn item are shown in Table $5.81 .9 \%$ of the medical students reported not feeling adequately confident in their ability to counsel parents about the diagnosis of their child with ASDs, $90.6 \%$ of the medical students reported not feeling adequately confident in their ability to prescribe medications for their child with ASDs, and $79.6 \%$ of the medical students reported not feeling adequately confident in their ability to counsel parents about the medication profile and side effects of prescriptions being used for the treatment of their child with
ASDs. On the other hand, $74.8 \%$ of the medical students reported that they might benefit from taking additional education or training in the area of ASDs and $81.9 \%$ of the medical students reported that the medical school curriculum should include a separate course or lecture in the area of ASDs.

\section{Associations between sociodemographic and academic variables of the students with familiarity, knowledge, and confidence scores}

Associations between sociodemographic and academic variables of the students with familiarity, knowledge, and confidence scores are shown in Table 6.

Scoring $\geq 50 \%$ on the familiarity items was significantly associated with having a course/part of a course on ASDs (Pearson Chi-Square/Fisher's Exact test = $20.39, p$-value $<0.001)$. Other sociodemographic and academic variables were not significantly associated with the familiarity scores. Scoring $\geq 50 \%$ on the knowledge items was significantly associated with academic stage (Pearson Chi-Square/Fisher's Exact test $=18.93, p$-value $<0.001$ ), having a course/part of a course on ASDs (Pearson Chi-Square/Fisher's Exact test $=26.56, p$-value $<0.001$ ), and having interacted with someone with autism spectrum disorder (Pearson Chi-Square/Fisher's Exact test $=6.91, p$-value $=0.011)$. Other sociodemographic and academic variables were not significantly associated with the knowledge scores. Scoring $\geq 50 \%$ on the confidence and willingness items was significantly associated with satisfaction with academic achievement (Pearson Chi-Square/Fisher's Exact test $=5.67, p$-value $=$ 0.049 ) and satisfaction with social status (Pearson ChiSquare $/$ Fisher's Exact test $=5.69, p$-value $=0.029)$. Other sociodemographic and academic variables were not significantly associated with the confidence and willingness scores.

Logistic regression showed that the medical students who have had a course/part of a course on ASDs were

Table 5 Confidence of the medical students to provide care/counsel people with ASDs and willingness to learn about ASDs

\begin{tabular}{|c|c|c|c|c|c|c|c|c|c|c|c|}
\hline \multirow[b]{2}{*}{$\underline{\#}$} & \multirow[b]{2}{*}{ Confidence item } & \multicolumn{2}{|c|}{$\begin{array}{l}\text { Strongly } \\
\text { disagree }\end{array}$} & \multicolumn{2}{|c|}{ Disagree } & \multicolumn{2}{|c|}{ Neutral } & \multicolumn{2}{|c|}{ Agree } & \multicolumn{2}{|c|}{$\begin{array}{l}\text { Strongly } \\
\text { agree }\end{array}$} \\
\hline & & $\mathbf{n}$ & $\%$ & $\mathbf{n}$ & $\%$ & $\mathbf{n}$ & $\%$ & $\mathbf{n}$ & $\%$ & $\mathbf{n}$ & $\%$ \\
\hline 1 & $\begin{array}{l}\text { I feel confident in my abilities to counsel parents with regard to diagnosis } \\
\text { of their child with ASDs }\end{array}$ & 32 & 10.4 & 82 & 26.5 & 139 & 45.0 & 48 & 15.5 & 8 & 2.6 \\
\hline 2 & I feel confident in my abilities to prescribe drugs for their child with ASDs & 101 & 32.7 & 97 & 31.4 & 82 & 26.5 & 22 & 7.1 & 7 & 2.3 \\
\hline 3 & $\begin{array}{l}\text { I feel confident in my abilities to counsel parents about the drug profile and } \\
\text { side effects of prescriptions being used for the treatment of their child } \\
\text { with ASDs }\end{array}$ & 54 & 17.5 & 101 & 32.7 & 91 & 29.4 & 49 & 15.9 & 14 & 4.5 \\
\hline 4 & $\begin{array}{l}\text { I feel that I could benefit from taking additional education or training in the } \\
\text { area of ASDs }\end{array}$ & 8 & 2.6 & 21 & 6.8 & 49 & 15.9 & 136 & 44.0 & 95 & 30.7 \\
\hline 5 & $\begin{array}{l}\text { I feel that the medical school curriculum should include a separate course } \\
\text { or lecture in the area of ASDs }\end{array}$ & 7 & 2.3 & 7 & 2.3 & 42 & 13.6 & 127 & 41.1 & 126 & 40.8 \\
\hline
\end{tabular}




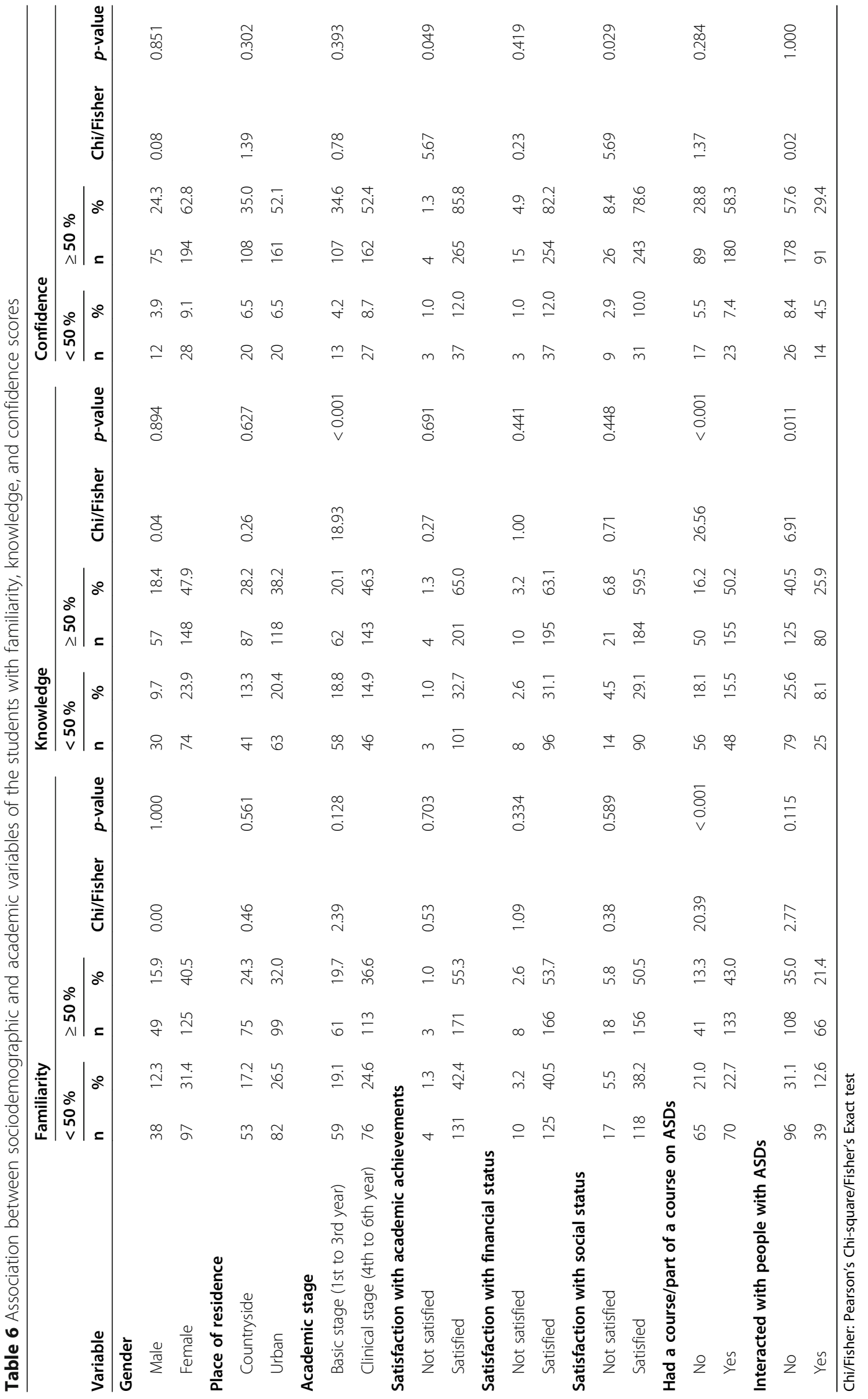


3.08 -fold (95\% C.I. of 1.78-5.31) more likely to score $\geq$ $50 \%$ on the familiarity items compared to those who did not have a course/part of a course on ASDs. The medical students who were in their clinical academic stage (4th to 6th year) were 2.36 -fold (95\% C.I. of 1.34-4.18) more likely to score $\geq 50 \%$ on the knowledge items compared to those who were in their basic stage (1st to 3rd year), those who have had a course/part of a course on ASDs were 2.66 -fold (95\% C.I. of 1.52-4.65) more likely to score $\geq 50 \%$ on the knowledge items compared to those who did not have a course/part of a course on ASDs, and the medical students who had interacted with someone with ASDs were 2.59-fold (95\% C.I. of 1.444.63) more likely to score $\geq 50 \%$ on the knowledge items compared to those who had not interacted with someone with ASDs. Medical students who reported high satisfaction with their social life were 2.84 -fold ( $95 \%$ C.I. of 1.15-7.00) more likely to score $\geq 50 \%$ on the confidence items compared to those who reported low satisfaction with their social life. Details of the logistic regression model are shown in Table 7.

\section{Discussion}

Medical students are the future workforce of physicians in all specialties in primary, secondary, tertiary, and highly specialized care centers. As a backbone of healthcare provision in any healthcare system, physicians should be adequately trained to care for individuals including those with ASDs. This multicenter study is the first attempt to assess familiarity, knowledge, confidence, and willingness to learn of medical students on the different aspects of ASDs. Several awareness and knowledge gaps were identified among the medical students trained in Palestinian universities with regard to symptoms, diagnosis, treatment options, and community resources to help people with ASDs and their families.

Findings of this study showed that familiarity of medical students with regard to symptoms, diagnosis, treatment options, and community resources to help people with ASDs and their families was inadequate as indicated by the median familiarity score. In this study, the median familiarity score was $50 \%(42.5 \%$, $57.5 \%)$. Findings of this study were consistent with those reported

Table 7 Factors associated with familiarity, knowledge, and confidence scores

\begin{tabular}{|c|c|c|c|c|c|c|c|c|}
\hline \multirow[b]{2}{*}{ Dimension } & \multirow[b]{2}{*}{ Variable } & \multirow[b]{2}{*}{$\beta$} & \multirow[b]{2}{*}{ S.E. } & \multirow[b]{2}{*}{ Wald } & \multirow[b]{2}{*}{$p$-value } & \multirow[b]{2}{*}{ O.R. } & \multicolumn{2}{|c|}{$95 \%$ C.I. for O.R. } \\
\hline & & & & & & & Lower & Upper \\
\hline \multirow[t]{8}{*}{ Familiarity } & Gender & 0.02 & 0.27 & 0.01 & 0.941 & 1.02 & 0.60 & 1.73 \\
\hline & Place of residence & 0.22 & 0.25 & 0.77 & 0.381 & 1.24 & 0.77 & 2.01 \\
\hline & Academic stage & -0.04 & 0.28 & 0.03 & 0.874 & 0.96 & 0.56 & 1.65 \\
\hline & Satisfaction with academic achievements & -0.32 & 0.83 & 0.15 & 0.702 & 0.73 & 0.14 & 3.68 \\
\hline & Satisfaction with financial status & -0.48 & 0.53 & 0.82 & 0.366 & 0.62 & 0.22 & 1.75 \\
\hline & Satisfaction with social status & 0.18 & 0.38 & 0.21 & 0.646 & 1.19 & 0.56 & 2.51 \\
\hline & Had a course/part of a course on ASDs & 1.12 & 0.28 & 16.31 & $<0.001$ & 3.08 & 1.78 & 5.31 \\
\hline & Interacted with people with ASDs & 0.47 & 0.26 & 3.28 & 0.070 & 1.60 & 0.96 & 2.68 \\
\hline \multirow[t]{8}{*}{ Knowledge } & Gender & -0.06 & 0.29 & 0.04 & 0.851 & 0.95 & 0.53 & 1.68 \\
\hline & Place of residence & 0.28 & 0.27 & 1.07 & 0.301 & 1.32 & 0.78 & 2.24 \\
\hline & Academic stage & 0.86 & 0.29 & 8.77 & 0.003 & 2.36 & 1.34 & 4.18 \\
\hline & Satisfaction with academic achievements & 0.00 & 0.84 & 0.00 & 0.998 & 1.00 & 0.19 & 5.16 \\
\hline & Satisfaction with financial status & -0.42 & 0.56 & 0.57 & 0.451 & 0.65 & 0.22 & 1.97 \\
\hline & Satisfaction with social status & 0.30 & 0.40 & 0.56 & 0.456 & 1.35 & 0.61 & 2.98 \\
\hline & Had a course/part of a course on ASDs & 0.98 & 0.29 & 11.68 & 0.001 & 2.66 & 1.52 & 4.65 \\
\hline & Interacted with people with ASDs & 0.95 & 0.30 & 10.20 & 0.001 & 2.59 & 1.44 & 4.63 \\
\hline \multirow[t]{8}{*}{ Confidence } & Gender & -0.31 & 0.39 & 0.62 & 0.432 & 0.73 & 0.34 & 1.58 \\
\hline & Place of residence & -0.46 & 0.36 & 1.66 & 0.198 & 0.63 & 0.31 & 1.27 \\
\hline & Academic stage & -0.76 & 0.42 & 3.24 & 0.072 & 0.47 & 0.21 & 1.07 \\
\hline & Satisfaction with academic achievements & -1.58 & 0.87 & 3.29 & 0.070 & 0.21 & 0.04 & 1.14 \\
\hline & Satisfaction with financial status & -0.07 & 0.71 & 0.01 & 0.918 & 0.93 & 0.23 & 3.71 \\
\hline & Satisfaction with social status & 1.04 & 0.46 & 5.13 & 0.023 & 2.84 & 1.15 & 7.00 \\
\hline & Had a course/part of a course on ASDs & 0.65 & 0.40 & 2.66 & 0.103 & 1.91 & 0.88 & 4.15 \\
\hline & Interacted with people with ASDs & -0.17 & 0.37 & 0.21 & 0.647 & 0.84 & 0.40 & 1.75 \\
\hline
\end{tabular}


among other healthcare providers like practicing pharmacists in Palestine and nurses in Virginia [6, 33]. On the other hand, familiarity of medical students in this study were relatively lower compared to pharmacists and pharmacy students in Mississippi as indicated by the percentages of participants rating familiarity items as not familiar at all or not familiar compared to the percentages of those who rated the familiarity items as familiar or completely familiar [5, 34]. In this study, a worrisomely high percentage of medical students (78.6\%) reported inadequate familiarity with signs and symptoms of ASDs. Additionally, the vast majority of the medical students in this study reported inadequate familiarity with the diagnostic tools used in the diagnosis of ASDs. In clinical practice, signs and symptoms are important for differential diagnosis of diseases and disorders $[35,36]$. Physicians and future physicians should be able to recognize signs and symptoms of diseases and disorders and should be able to make diagnosis. Inability to recognize signs and symptoms of a disease or disorder would hinder physicians from making correct diagnosis and subsequently manage the disease. Today, medications like risperidone and aripiprazole are approved for the management of some behavioral symptoms of ASDs [14-17]. While data from real-world practice showed that aripiprazole was generally effective and welltolerated in the management of irritability associated with ASDs among children and adolescents [37], other studies found that relapse rates were not different between pediatric patients with ASDs who were randomized to receive aripiprazole compared to those who were randomized to receive placebo [38]. These findings suggested re-evaluating the use of aripiprazole following a period of stabilizing the patients. In this study, the majority of the medical students reported inadequate familiarity with the medications used in the treatment of behavioral symptoms of ASDs, their doses, and adverse effects. This might have future implications on the quality of healthcare provided to individuals with ASDs as physicians are the ones who prescribe medications to patients. In many healthcare systems, physicians are the only authorized healthcare providers to prescribe medications to patients [39]. Physicians are supposed to prescribe the right medications, with right doses, at the right frequency, and for the right period of time. Physicians should also be knowledgeable of the potential adverse effects that could be associated with the use of these medications [40]. Physicians are the primary source of information for patients in many healthcare systems around the world [41]. Therefore, physicians should be able to help individuals with ASDs and their families/caregivers sort through information and make informed decisions. In this study, the majority of medical students reported inadequate familiarity with community resources in their region and how to help families make informed decisions. This might affect their ability to perform their expected roles in caring for individuals with ASDs.

When knowledge of medical students with regard to etiology, prevalence, and treatment of ASDs was tested, several low awareness areas were identified. In this study, the majority of the medical students either answered incorrectly or did not know that ASDs were more prevalent than juvenile diabetes $(87.1 \%)$ and Down syndrome $(78.6 \%)$. Surprisingly, these percentages were higher than those reported among community pharmacists in Palestine, pharmacists, and pharmacy students in Mississippi [5, 6, 34]. In this study, the majority of medical students $(82.8 \%)$ either answered incorrectly or did not know that risperidone and aripiprazole were approved for the treatment of the behavioral symptoms of ASDs. Despite some high awareness areas like awareness of impairments in social interaction, communication or language, and behavioral development among children with ASDs which was correctly answered by $93.2 \%$ of medical students. Several knowledge gaps were identified as indicated by the number of incorrect answers/I don't know answers. Together, results reported in this study highlighted the need to improve knowledge of future physicians with regard to etiology, prevalence, and treatment of autism spectrum. In this study, $33 \%$ of medical students did not correctly answer the question on the myth that linked vaccines to ASDs. Physicians are highly trusted by the society. Therefore, physicians are in key position to influence decisions of parents to vaccinate their children [42]. In different countries around the world, myths have always augmented vaccine hesitancy [43]. Findings of this study highlighted the need to dispel this myth among medical students.

In this study, receiving a course/part of a course on ASDs was a predictor of higher familiarity and knowledge with regard to ASDs. Findings of this study were consistent with those previously reported among practicing pharmacists in Palestine [6]. Previous studies have shown that receiving courses can increase familiarity and knowledge of healthcare providers including physicians on different healthcare conditions $[27,44,45]$. Interestingly, medical students who interacted with people with ASDs were more likely to score $50 \%$ and more in the knowledge test. These findings were not surprising as interacting with patients with a certain condition might stimulate curiosities and knowledge seeking behavior $[46,47]$. In this study, medical students who reported higher satisfaction with their social life were more likely to score $50 \%$ and more on the confidence and willingness to learn items. Probably, those students were more social and willing to interact with people including those with ASDs. 


\section{Strengths and limitations}

Results of this study should be interpreted considering a number of strength and limitation points. First, this is the first multicenter study to assess familiarity, knowledge, confidence, and willingness to learn of medical students about symptoms, diagnosis, treatment options, and community resources to help people with ASDs and their families. Second, medical students who participated in this study were diversified in terms of gender, academic year, place of residence, and interaction with people with ASDs. Third, the study tool used in this study was previously validated and used among healthcare providers in different settings. Although the tool was previously assessed for reliability and internal consistency, the tool was revalidated among medical students using appropriate statistical tests. Fourth, data obtained in this study were analyzed consecutively using multiple statistical tests. On the other hand, the study had a number of limitations. First, the questionnaire used in this study oversimplified the reality of familiarity and knowledge of ASDs. More studies are still needed to understand what factors contribute to lack of knowledge of ASDs among the medical students. It is noteworthy mentioning that behavioral, communicational, and rehabilitation services are the primary services provided to individuals with ASDs. These services are often provided by specialty providers. Second, the questionnaire used multiple-choice questions. Multiple-choice questions are biased by design as they provide pre-conceived answers that the participant would choose from. Probably, an objective structured clinical examination could provide more insights into the ability of medical students to assess individuals with ASDs. Third, the sample size of this study was relatively small. However, medical students were recruited from the 3 major universities in Palestine. Additionally, the sample size used in this study was larger than those used in previous studies that assessed knowledge of healthcare providers with regard to ASDs [5, 34].

Findings of this study could be informative to decision and policy makers in academia, healthcare, advocacy groups, and professional associations who might need to design appropriate measures to improve familiarity, knowledge, and confidence of medical students in caring for individuals with ASDs.

\section{Conclusion}

Medical students are the future workforce of physicians in all healthcare settings including those providing healthcare services to individuals with ASDs. The present study identified considerable awareness and knowledge gaps among medical students with regard to ASDs. Medical students in this study reported low confidence in their ability to provide healthcare services for children with ASDs. Appropriately designed educational interventions might improve familiarity, knowledge, and confidence of medical students. More studies are still needed to investigate if such interventions can improve healthcare services for individuals with ASDs

\section{Supplementary Information}

The online version contains supplementary material available at https://doi. org/10.1186/s12909-021-02865-8.

\section{Additional file 1}

\section{Acknowledgements}

Author would like to thank the students who participated in the study. AnNajah National University is acknowledged for making this study possible.

\section{Authors' contributions}

$\mathrm{RS}$ and $\mathrm{MJ}$ were involved in the conception and design of the work, analysis and interpretation of data, drafting and final approval the manuscript. NY, FJ, and SR collected data and participated in drafting the manuscript. The author(s) read and approved the final manuscript.

\section{Authors' information}

Ramzi Shawahna, Associate Professor, Department of Physiology, Pharmacology and Toxicology, Faculty of Medicine and Health Sciences, An-Najah National University, Nablus, Palestine, An-Najah BioSciences Unit, Centre for Poisons Control, Chemical and Biological Analyses, AnNajah National University, Nablus, Palestine. Mohammad Jaber, Assistant Profession, Department of Medicine, Faculty of Medicine and Health Sciences, An-Najah National University Hospital, An-Najah National University, Nablus. Nourhan Yahya, Firdaous Jawadeh, Shahd Rawajbeh were MD candidates at the time of the study.

\section{Funding}

This study did not receive any specific funding.

\section{Availability of data and materials}

All data relevant to this study were included in the manuscript or provided as supplementary materials. The datasets used and/or analyzed during the current study are available from the corresponding author on reasonable request.

\section{Declarations}

Ethics approval and consent to participate

This multicenter cross-sectional study was conducted in adherence to the international guidelines and regulations including those in the Declaration of Helsinki and the ones followed at An-Najah National University. The study received ethical approval from the Institutional Review Board of An-Najah National University. The medical students who participated in this study provided written informed consent.

Consent for publication

Not applicable.

Competing interests

Authors report no competing interests.

\section{Author details}

${ }^{1}$ Department of Physiology, Pharmacology and Toxicology, Faculty of Medicine and Health Sciences, An-Najah National University, P.O. Box 7, New Campus, Building: 19, Office: 1340, Nablus, Palestine. ${ }^{2}$ An-Najah BioSciences Unit, Centre for Poisons Control, Chemical and Biological Analyses, An-Najah National University, Nablus, Palestine. ${ }^{3}$ Department of Medicine, Faculty of Medicine and Health Sciences, An-Najah National University, Nablus, Palestine. ${ }^{4}$ An-Najah National University Hospital, An-Najah National University, Nablus, Palestine. 
Received: 28 April 2021 Accepted: 26 July 2021

\section{Published online: 10 August 2021}

\section{References}

1. Xu G, Strathearn L, Liu B, Bao W: Prevalence of Autism Spectrum Disorder Among US Children and Adolescents, 2014-2016. JAMA 2018, 319(1):81-82.

2. Wang F, Lu L, Wang S-B, Zhang L, Ng CH, Ungvari GS, Cao X-L, Lu J-P, Hou C-L, Jia F-J et al: The prevalence of autism spectrum disorders in China: a comprehensive meta-analysis. Int J Biol Sci 2018, 14(7):717-725.

3. Knopf A: Autism prevalence increases from 1 in 60 to 1 in 54: CDC. The Brown University Child and Adolescent Behavior Letter 2020, 36(6):4-4.

4. Maenner MJ, Shaw KA, Baio J, EdS, Washington A, Patrick M, DiRienzo M, Christensen DL, Wiggins LD, Pettygrove $S$ et al: Prevalence of Autism Spectrum Disorder Among Children Aged 8 Years - Autism and Developmental Disabilities Monitoring Network, 11 Sites, United States, 2016. MMWR Surveill Summ 2020, 69(4):1-12.

5. Khanna R, Jariwala K: Awareness and knowledge of autism among pharmacists. Research in Social and Administrative Pharmacy 2012, 8(5): 464-471.

6. Shawahna R, Fahed B, Qadri D, Sharawi L, Soroghli M, Dweik M: Awareness and Knowledge of Autism Spectrum Disorders Among Pharmacists: A Cross-Sectional Study in Palestinian Pharmacy Practice. Journal of Autism and Developmental Disorders 2017, 47(6):1618-1627.

7. Harrison AJ, Long KA, Tommet DC, Jones RN: Examining the Role of Race, Ethnicity, and Gender on Social and Behavioral Ratings Within the Autism Diagnostic Observation Schedule. Journal of Autism and Developmental Disorders 2017, 47(9):2770-2782.

8. Shawahna R: Palestine and Autism. In: Encyclopedia of Autism Spectrum Disorders. edn. Edited by Volkmar FR. New York, NY: Springer New York; 2017: 1-6.

9. Richa S, Khoury R, J JR, Chammay R, Kazour F, Bou Khalil R, Kheir W, Choueifaty D, Kouba-Hreich E, Gerbaka B et al: Estimating the prevalence of autism spectrum disorder in Lebanon. L'Encephale 2020, 46(6):414-419.

10. Chaaya M, Saab D, Maalouf FT, Boustany RM: Prevalence of Autism Spectrum Disorder in Nurseries in Lebanon: A Cross Sectional Study. J Autism Dev Disord 2016, 46(2):514-522.

11. Qiu S, Lu Y, Li Y, Shi J, Cui H, Gu Y, Li Y, Zhong W, Zhu X, Liu Y, et al. Prevalence of autism spectrum disorder in Asia: A systematic review and meta-analysis. Psychiatry Res. 2020;284.

12. Cañigueral R, Hamilton AFdC: The Role of Eye Gaze During Natural Social Interactions in Typical and Autistic People. Frontiers in Psychology 2019, 10(560).

13. Mody M, Shui AM, Nowinski LA, Golas SB, Ferrone C, O'Rourke JA, McDougle CJ: Communication Deficits and the Motor System: Exploring Patterns of Associations in Autism Spectrum Disorder (ASD). Journal of Autism and Developmental Disorders 2017, 47(1):155-162.

14. Birch RC, Foley K-R, Pollack A, Britt H, Lennox N, Trollor JN: Problems managed and medications prescribed during encounters with people with autism spectrum disorder in Australian general practice. Autism 2017, 22(8): 995-1004.

15. Kamimura-Nishimura K, Froehlich T, Chirdkiatgumchai V, Adams R, Fredstrom B, Manning P: Autism spectrum disorders and their treatment with psychotropic medications in a nationally representative outpatient sample: 1994-2009. Annals of Epidemiology 2017, 27(7):448-453.e441.

16. Poling A, Ehrhardt K, Li A: Psychotropic Medications as Treatments for People with Autism Spectrum Disorder. In: Handbook of Treatments for Autism Spectrum Disorder. edn. Edited by Matson JL. Cham: Springer International Publishing; 2017: 459-476.

17. Yu Y, Chaulagain A, Pedersen SA, Lydersen S, Leventhal BL, Szatmari P, Aleksic B, Ozaki N, Skokauskas N: Pharmacotherapy of restricted/repetitive behavior in autism spectrum disorder:a systematic review and meta-analysis. BMC Psychiatry 2020, 20(1):121.

18. Tural Hesapcioglu S, Ceylan MF, Kasak M, Sen CP: Olanzapine, risperidone, and aripiprazole use in children and adolescents with Autism Spectrum Disorders. Research in Autism Spectrum Disorders 2020, 72:101520.

19. Ballester P, Martínez MJ, Javaloyes A, Inda M-d-M, Fernández N, Gázquez P, Aguilar V, Pérez A, Hernández L, Richdale AL et al: Sleep problems in adults with autism spectrum disorder and intellectual disability. Autism Research 2019, 12(1):66-79.

20. Linke AC, Olson L, Gao Y, Fishman I, Müller R-A: Psychotropic Medication Use in Autism Spectrum Disorders May Affect Functional Brain Connectivity.
Biological Psychiatry: Cognitive Neuroscience and Neuroimaging 2017, 2(6): 518-527.

21. Young H, Oreve MJ, Speranza M: Clinical characteristics and problems diagnosing autism spectrum disorder in girls. Archives de Pédiatrie 2018, 25(6):399-403.

22. Martinez M, Thomas KC, Williams CS, Christian R, Crais E, Pretzel R, Hooper SR: Family Experiences with the Diagnosis of Autism Spectrum Disorder: System Barriers and Facilitators of Efficient Diagnosis. Journal of Autism and Developmental Disorders 2018, 48(7):2368-2378.

23. Alfageh BH, Wang Z, Mongkhon P, Besag FMC, Alhawassi TM, Brauer R, Wong ICK: Safety and Tolerability of Antipsychotic Medication in Individuals with Autism Spectrum Disorder: A Systematic Review and Meta-Analysis. Pediatric Drugs 2019, 21(3):153-167.

24. Thabrew H, Viswanathan A, Eggleston M, Moor S, Chinn D: Consensus or chaos: Survey of prescribing practices of New Zealand child and adolescent psychiatrists for children and adolescents with autism spectrum disorder. Research in Autism Spectrum Disorders 2020, 74:101553.

25. Farmer C, Leon J, Hommer R: Effective Medications for Treating Individuals with Autism Spectrum Disorder. In: School Psychopharmacology: Translating Research into Practice. edn. Edited by Carlson JS, Barterian JA. Cham: Springer International Publishing; 2019: 83-98.

26. Rhoades RA, Scarpa A, Salley B: The importance of physician knowledge of autism spectrum disorder: results of a parent survey. BMC Pediatrics 2007, 7(1):37.

27. McCormack G, Dillon AC, Healy O, Walsh C, Lydon S: Primary Care Physicians' Knowledge of Autism and Evidence-Based Interventions for Autism: A Systematic Review. Review Journal of Autism and Developmental Disorders 2020, 7(3):226-241.

28. Turk T, Elhady MT, Rashed S, Abdelkhalek M, Nasef SA, Khallaf AM, Mohammed AT, Attia AW, Adhikari P, Amin MA et al: Quality of reporting web-based and non-web-based survey studies: What authors, reviewers and consumers should consider. PLOS ONE 2018, 13(6):e0194239.

29. Sharma A, Minh Duc NT, Luu Lam Thang T, Nam NH, Ng SJ, Abbas KS, Huy NT, Marusic A, Paul CL, Kwok J et al: A Consensus-Based Checklist for Reporting of Survey Studies (CROSS). Journal of general internal medicine 2021

30. von Elm E, Altman DG, Egger M, Pocock SJ, Gotzsche PC, Vandenbroucke $J P$, Initiative S: The Strengthening the Reporting of Observational Studies in Epidemiology (STROBE) statement: guidelines for reporting observational studies. PLoS medicine 2007, 4(10):e296.

31. Luleci NE, Hidiroglu S, Karavus M, Karavus A, Sanver FF, Ozgur F, Celik M, Celik SC: The pharmacists' awareness, knowledge and attitude about childhood autism in Istanbul. International Journal of Clinical Pharmacy 2016, 38(6):1477-1482

32. Harrison AJ, Slane MM, Hoang L, Campbell JM: An international review of autism knowledge assessment measures. Autism 2016, 21(3):262-275.

33. Strunk JA: School Nurses' Knowledge of Autism Spectrum Disorders. The Journal of School Nursing 2009, 25(6):445-452

34. Khanna R, Jariwala K, Holmes ER, Ramachandran S: Autism familiarity and knowledge among pharmacy students. Currents in Pharmacy Teaching and Learning 2014, 6(1):150-157.

35. Harrington JW, Patrick PA, Edwards KS, Brand DA: Parental beliefs about autism: Implications for the treating physician. Autism 2006, 10(5):452-462.

36. Jacobs D, Steyaert J, Dierickx K, Hens K: Implications of an Autism Spectrum Disorder Diagnosis: An Interview Study of How Physicians Experience the Diagnosis in a Young Child. Journal of Clinical Medicine 2018, 7(10):348.

37. Sugimoto Y, Yamamura K, Takayama T, Fukuta Y, Aoki K, Mikami K, Tomoda A: Aripiprazole in the real-world treatment for irritability associated with autism spectrum disorder in children and adolescents in Japan: 52-week post-marketing surveillance. BMC Psychiatry 2021, 21(1):204.

38. Hirsch LE, Pringsheim T: Aripiprazole for autism spectrum disorders (ASD). The Cochrane database of systematic reviews 2016(6):CD009043.

39. Desroches J: Should prescribing authority be shared with nonphysicians? Canadian Family Physician 2009, 55(12):1177.

40. Ziegler DK, Mosier MC, Buenaver M, Okuyemi K: How Much Information About Adverse Effects of Medication Do Patients Want From Physicians? Archives of Internal Medicine 2001, 161(5):706-713.

41. Ellis AK, Boursiquot J, Carr S, Graham F, Masse M-S: Patient and physician perceptions of seasonal allergic rhinitis and allergen immunotherapy: a parallel physician patient survey. Allergy, Asthma \& Clinical Immunology 2020, 16(1):15 
42. Shen S, Dubey V: Addressing vaccine hesitancy. Canadian Family Physician 2019, 65(3):175.

43. Davidson M: Vaccination as a cause of autism-myths and controversies. Dialogues Clin Neurosci 2017, 19(4):403-407.

44. Austriaco K, Aban I, Willig J, Kong M: Contemporary Trainee Knowledge of Autism: How Prepared Are Our Future Providers? Frontiers in Pediatrics 2019, 7(165).

45. van 't Hof M, van Berckelaer-Onnes I, Deen M, Neukerk MC, Bannink R, Daniels AM, Hoek HW, Ester WA: Novel Insights into Autism Knowledge and Stigmatizing Attitudes Toward Mental Illness in Dutch Youth and Family Center Physicians. Community Mental Health Journal 2020, 56(7):1318-1330.

46. Morris R, Greenblatt A, Saini M: Healthcare Providers' Experiences with Autism: A Scoping Review. Journal of Autism and Developmental Disorders 2019, 49(6):2374-2388.

47. Altay MA: Family Physicians' Awareness of Autism Spectrum Disorder: Results from a Survey Study. Open Access Maced J Med Sci 2019, 7(6): 967-972.

\section{Publisher's Note}

Springer Nature remains neutral with regard to jurisdictional claims in published maps and institutional affiliations.

\section{Ready to submit your research? Choose BMC and benefit from:}

- fast, convenient online submission

- thorough peer review by experienced researchers in your field

- rapid publication on acceptance

- support for research data, including large and complex data types

- gold Open Access which fosters wider collaboration and increased citations

- maximum visibility for your research: over $100 \mathrm{M}$ website views per year

At $\mathrm{BMC}$, research is always in progress.

Learn more biomedcentral.com/submissions 